\title{
Ciliary Neurotrophic Factor Disturbances in Patients with Melancholic Depression
}

\author{
Uzbekov MG* and Shikhov S \\ Moscow Research Institute of Psychiatry, Russia
}

Received: 制 January 11, 2019; Published: 盋 January 23, 2019

*Corresponding author: Uzbekov MG, Laboratory of Brain Pathology, Moscow Research Institute of Psychiatry, Moscow, Russia

\section{Short Communication}

Ciliary neurotrophic factor (CNTF) is a 22-kDa cytokine belonging to the interleukin- 6 family and is mainly expressed in glial cells of the central and peripheral nervous systems [1]. Ciliary neurotrophic factor is a neurotrophin which could act as a neuroprotective agent [2]. CNTF plays an important role in the regulation of neuronal development, neuroprotection and may also influence cognitive processes [3]. However, the physiological relevance of circulating CNTF still needs to establish. Depression is one of the most prevalent mental disorders and one of the main causes of disability worldwide. Depression now is a very complicated medical and social problem that in the next years will be only exacerbate. Thus, investigation of all aspects of pathogenetic mechanisms of depression is a very important task of the medicine [4]. Depression is characterized by an altered monoaminergic neurotransmission as well as a modulation of cytokines and other mediators in the central nervous system. In particular, disturbed neurotrophic factors may influence affective behavior including depression and anxiety [3]. There have been several reports regarding the detection of circulating CNTF in healthy individuals, patients with septic shock, systemic lupus erythematosus, rheumatoid arthritis, multiple myeloma and amyotrophic lateral sclerosis [1]. But there are no reports in the literature regarding circulating levels of CNTF in depression. The aim of the study was to investigate the levels of CNTF in blood serum in patients with melancholic depression.

\section{Subjects and Methods}

There were investigated 27 patients with melancholic depression at admission in the clinic of affective disorders of Moscow Research Institute of Psychiatry and 11 healthy volunteers (controls). Patient's state was defined as a depressive episode in the frame of bipolar depressive disorder (type 2) (F32) and in the structure of recurrent depressive disorder (F33). Investigation was performed in accordance with Helsinki Declaration and the conclusion of local ethical committee of the Institute (№ 16 of 13.03.2017). CNTF concentration in blood serum was assessed by ELISA method using Thermo scientific multiskan FC (China) and Human Ciliary Neurotrophic Factor (hCNTF) ELISA kit, Cat. CSBE-04527h (Cusabio Technology LLC, USA). Statistical analysis was performed using Wilcoxon-Mann-Whitney u-test. The difference was considered as significant at $\mathrm{p}<0.05$.

\section{Results and Discussion}

At admission, before any treatment CNTF concentration in blood serum of patients with melancholic depression was 679.11 $\pm 63.09 \mathrm{pg} / \mathrm{ml}$ of serum. It was significantly for $71.7 \%$ higher in comparison with healthy subjects $(405.96 \pm 91.91 \mathrm{pg} / \mathrm{ml}$ of serum, $\mathrm{p}<0.01$ ). It is shown the first time in the literature that depression, in particular melancholic depression, is followed by increased of ciliary neurotrophic factor level in blood serum. Earlier we have shown that CNTF concentration was increased in patients with epilepsy $[5,6]$. As it was said above CNTF plays an important role in neuroprotection and may influence cognitive processes [3]. It was shown that depression is followed by increased permeability of blood-brain barrier [7]. We can hypothesize that in pathological condition CNTF is synthesized and secreted in the brain in larger amounts, but it does not exhibit neuroprotective properties because it immediately leaks out into the blood stream through the damaged blood-brain barrier [6]. The similar changes were found in patients with autism spectrum disorders [2]. In conclusion we can state that in some clinical conditions - depression, autism, etc - ciliary neurotrophic factor cannot reveal its neuroprotective functions because of damaged blood-brain barrier, influences of oxidative stress on CNTF synthesis machinery and some other. Further investigations must be performed. 


\section{References}

1. Akahori Y, Takumoto N, Masumoto A, Inoue S, Nakatsukasa H, et al. (2010) Circulating levels of ciliary neurotrophic factor in normal pregnancy and preeclampcia. Acta Mea Okayama 64(2): 129-136.

2. Brondino N, Rocchetti M, Fusar-Poli L, Damiani S, Goggi A, et al. (2018) Increased CNTF levels in adults with autism spectrum disorders. World J Biol Psychiatry 19: 1-5.

3. Peruga I, Hartwig S, Merkler D, Thöne J, Hovemann B, et al. (2012) Endogenous ciliary neurotrophic factor modulates anxiety and depressive-like behavior. Behav Brain Res 229(2): 325-332.

4. Uzbekov MG, Syrejshchikova TI, Smolina NV, Brilliantova VV, Dobretsov GE, et al. (2018) Serum albumin conformation in patients with

\section{ISSN: 2574-1241}

DOI: $10.26717 /$ BJSTR.2019.13.002408

Uzbekov MG. Biomed J Sci \& Tech Res

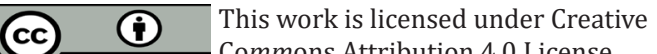

Submission Link: https://biomedres.us/submit-manuscript.php melancholic depression under antidepressant therapy. Biomedical Journal of Scientific and Technical Research 7(3): 1-2.

5. Musina LO, Uzbekov MG (2017) Changes in the ciliary neurotrophic factor are related to the degree of severity of epilepsy. Neurochem J 11(1): 112-114.

6. Uzbekov M, Musina L (2018) Serum ciliary neurotrophic factor concentration as a potential biomarker of efficacy of citicoline pharmacotherapy of temporal-lobe epilepsy in women. Theranostics of Brain, Spine \& Neural Disorders 3(4): 1-2.

7. Najjar S, Pearlman D, Devinsky O, Najjar A, Zagzag D (2013) Neurovascular unit dysfunction with blood-brain barrier hyperpermeability contributes to major depressive disorder: a review of clinical and experimental evidence. Journal of Neuroinflammation 10: 142-158.

\begin{tabular}{ll} 
BIOMEDICAL & Assets of Publishing with us \\
RESEARCHES & - Global archiving of articles \\
& - Immediate, unrestricted online access \\
\hline
\end{tabular}

